\title{
América Latina entre narrativas influyentes y tiempos de historia global
}

\section{Latin America between Prominent Narratives and the Age of Global History}

\author{
Carlos Riojas \\ Universidad de Guadalajara, Jalisco, México, email: criojas@cucea.udg.mx
}

Resumen. El objetivo de este artículo es determinar cuál es el peso específico que ha adquirido América Latina en las narrativas de la historia global o mundial. La evidencia al respecto se ha recabado de la Journal of World History y la Journal of Global History. La exposición se divide en cuatro partes. Primero, se exponen las narrativas influyentes sobre América Latina; luego, se exploran las publicaciones de la Journal of World History para saber cuánto se escribe en términos absolutos y relativos sobre América Latina como tema principal; posteriormente se hace lo propio con la Journal of Global History; por último, se contextualizan los resultados obtenidos apoyados en el reconocimiento de factores explicativos que nos ayuden a entender el quehacer histórico desde un enfoque institucional.

Palabras clave: historia global; historia mundial; América Latina y el Caribe; periferia; centro.

Abstract. The article has as objective to determine what is the specific weight that Latin America has acquired as main topic in the narratives of global or world history. I have used as evidences the Journal of World History and Journal of Global History. The paper is organized as follow: first, I made a brief reference to these metanarratives and Latin America; then, I explore the publication of the Journal of World History to identify how much has been written, in absolute and relative terms, about Latin America as main topic; after, I apply the same methodology to the Journal of Global History; finally, I try to contextualize the results based in the recognition of several factors that help us to understand the conditions to make history under an institutional perspective.

Key words: global history; world history; Latin America and Caribbean; periphery; core.

JEL: N01; N10; N90; O50; O54

Fecha de recepción: 12 de julio de 2017. Fecha de aceptación: 1 de noviembre de 2017.

Organismo colaborador: Consejo Nacional de Ciencia y Tecnología de México, núm. ref. CB-2012-177133. 


\section{INTRODUCCIÓN}

$\mathrm{E}$ 131 de enero de 1979 se llevó a cabo una ceremonia en la Casa Blanca de Washington, en Estados Unidos, con motivo de la primera visita oficial por parte de un jefe de Estado de un país comunista. Deng Xiaoping -secretario general del Comité Central del Partido Comunista Chino- fue recibido para firmar oficialmente un acuerdo sobre ciencia y tecnología entre ambas naciones; en noviembre de 1978 también estuvo en el Reino Unido. La visita causó expectación entre los estadunidenses, quienes estuvieron dispuestos a pagar más de 1000 dólares para asistir a dicha celebración en el Centro Kennedy. El autor intelectual de la iniciativa fue Zbigniew Brzezinski. El entusiasmo fue igualmente compartido por los políticos estadunidenses. Según informó The Economist, se pudo apreciar a los congresistas de aquel entonces esperando en la fila para obtener un autógrafo de Deng Xiaoping, ${ }^{1}$ escena poco común para la época. El discurso del líder chino fue moderado e inteligente, evitó la palabra liberación al sustituirla por unificación; no tocó el tema de Taiwán, sino más bien, canalizó sus esfuerzos diplomáticos para llegar a un acuerdo comercial con Estados Unidos bajo la denominación de nación más favorecida, lo que demostraba un profundo entendimiento de la política interna estadunidense, incluso aún más penetrante que los conocimientos adquiridos en la materia por los soviéticos. Para algunos observadores, la China comunista promovía la ilusión de que había regresado al mundo. ${ }^{2}$ Pero, ciacaso esta visita oficial a Estados Unidos realmente equivalía a un eventual retorno al mundo? ¿De qué mundo estamos hablando: bipolar, tripolar, multipolar, etcétera?

Dado el escenario de guerra fría que se vivía en aquel año de la visita de Deng Xioaping a Estados Unidos, este acto no coincidía plenamente con el imaginario tradicional de este periodo histórico (1947-1989, 1991), tal como lo muestra la expectativa del público y los políticos estadunidenses en general. Más bien, se puede tomar como un antecedente de los tiempos que se avecinarían. No se trataba, tampoco, de una simple relación intercultural entre Occidente y Oriente, se comenzaban a dibujar los primeros trazos de un proyecto global contemporáneo (Pérez, 2014, p. 347). La dicotomía entre un Global South y un Global North sería pronto superada ante la irrupción de nuevos actores en la escena que configuraría lentamente un papel destacado de un Global East, que también ha sido reconocido por otros estudiosos (Sachsenmaier, 2011, p. 16). Asimismo, China era uno de los mejores representantes de la transformación econó-

\footnotetext{
1 "How Mr. Deng won Washington", The Economist, 3 de febrero de 1979, p. 23.

2 "Salt on their tails", The Economist, 3 de febrero de 1979, p. 11.
} 
mico-institucional de Oriente, especialmente a partir de 1979 (Riojas, 2017, p. 396); no sólo rebasó a los Tigres Asiáticos (Corea del Sur, Taiwán, Singapur y Hong Kong) respecto al poderío económico, sino que delineó en gran medida una época que se traslapó con un periodo histórico anterior (guerra fría), sobre todo si se concibe desde una perspectiva occidental. Independientemente de estas interconexiones que se configuraba entre Asia, América del Norte y, en menor medida, Europa, nos cuestionamos lo siguiente: ¿qué papel desempeñaba América Latina en este escenario que comenzaba a esbozar el advenimiento de un nuevo periodo histórico? ¿Por qué una visita a Estados Unidos por parte del alto mando del Partido Comunista Chino equivalía, en términos de aquellos años, a una apertura al mundo? ¿Existe una relación entre el repunte económico-institucional de Asia en general, basado en una nueva plataforma tecnológica, con la producción académica inscrita en lo que se ha denominado historia global?

Si nos detenemos por un momento en el periodo histórico conocido como guerra fría, destaca que América Latina aparece, de manera general, como un protagonista periférico, no obstante la trascendencia de los casos de Cuba (1956 y 1962), Chile (1973) o Nicaragua (1979). Dentro de esta misma vertiente, cuando el gobierno de Estados Unidos promueve iniciativas intervencionistas mediante la Agencia Central de Inteligencia (CIA, por sus siglas en inglés) estos hechos forman parte de una metanarrativa entre Estados Unidos y los otros poderes (Berger, Easterly, Nunn y Satyanath, 2013, p. 866); también la guerra fría puede ser vista como el inicio de una era militar de carácter nuclear, que se relaciona con el calentamiento global para darle sentido a una longue durée marcada por este permanente riesgo que se acompaña con el crecimiento de la población y las ciudades, pero sin hacer referencia precisa a la situación de América Latina (Rogers, 2014, pp. 93-94); incluso, la guerra fría puede apreciarse como una historia local conectada con aquella de índole global, mediante la transformación del paisaje derivada del Proyecto Manhattan, cuyo complejo militar de máxima seguridad en Estados Unidos cambió la vida de los ecosistemas del espacio conocido como Cuatro Esquinas (Arizona, Nuevo México, Nevada y California), con la finalidad de atender riesgos autoconstruidos como la histeria antimexicana de los estados fronterizos de la unión estadunidense (Piette, 2011, pp. 391 y 393); de igual forma América Latina resulta marginal cuando se ve a la guerra fría como un movimiento asociado a ese conjunto difuso de países que lo denominan tercer mundo, que si bien es cierto no se puede concebir de manera aislada respecto a lo que pasa en otras partes del planeta, no menos cierto es que su deconstrucción resulta un tanto complicada cuando muchas de sus relaciones políticas, económicas y sociales dependen de lo que suceda en otras partes del mundo (Cox, 2011, pp. 1108-1109); parece ser que sólo América Latina adquie- 
re un lugar central cuando se atiende el enfoque de los estudios de área, es decir, explicar los impactos de la guerra fría desde y en América Latina, pero sólo para América Latina, aunque existen muchas posibilidades de interconectar estos eventos con otros de carácter global (Rochlin, 2011, pp. 237 y 241). De igual forma, llama la atención que en la sexta edición de The penguin history of the world (Roberts y Westad, 2013) no se dedique ninguno título de sus 54 capítulos a América Latina, mientras que a Asia se le dedican expresamente catorce y a Europa al menos diez. Para este, como para otros periodos de la historia global, destaca una marcada influencia de la perspectiva anglosajona a pesar de los diversos intentos por presentar una periodización alternativa a este conjunto de hechos (Hausberger, 2013, p. 89; Pérez, 2014, pp. 339, 347). Entonces, por lo que concierne a América Latina y su hipotético protagonismo periférico a nivel mundial, respecto a lo que sucede con Europa o Asia, nos preguntamos si esta situación es acaso una incómoda coincidencia de los hechos mencionados o, en su defecto, ¿es una manifestación con un carácter más sistémico en la construcción y la propagación de influyentes narrativas históricas adscritas a las visiones que se emanan de lo que conocemos como historia global?

Por lo tanto, el presente ensayo tiene como objetivo explorar con mayor detalle cuál es el peso específico y ponderado que ha adquirido América Latina en las metanarrativas históricas como aquellas directamente asociadas a las historias mundial y global. Para alcanzar dicho objetivo decidimos explorar desde el punto de vista cuantitativo dos revistas científicas líderes en su ramo como son la Journal of World History y la Journal of Global History, con el fin de sopesar de manera concreta el papel que adquiere América Latina como un área de estudio en el mencionado concierto narrativo. Con base en ello, hemos dividido la exposición en cuatro partes. Primero se hace una breve referencia a las narrativas influyentes y América Latina; luego se exploran con cierto detalle los trabajos publicados en la Journal of World History con la finalidad de saber cuánto se escribe, tanto en términos absolutos como relativos, sobre América Latina como tema principal; posteriormente, con base en una metodología similar se hace lo propio con la Journal of Global History; por último, tratamos de contextualizar los resultados obtenidos apoyados en las tradiciones que existen en el quehacer histórico desde un enfoque individual e institucional. El texto termina con algunas consideraciones finales. 


\section{LAS NARRATIVAS INFLUYENTES Y AMÉRICA LATINA}

Diferentes generaciones de historiadores -especialmente estudiosos del periodo colonial, del siglo XIX y de principios del $\mathrm{XX}-$, han señalado la relativa marginación de América Latina en las grandes narrativas de la historia global o mundial (Bonialian, 2017; Brown, 2015; Hausberger, 2013; Rinke, 2017; Semo, 1989); incluso, esta falta de atención no es sólo señalada en los círculos de estudio latinoamericanistas, sino más bien, se considera que ha sido una postura intelectual frecuente por parte de algunos académicos en Occidente, específicamente en Europa occidental y en Estados Unidos, donde persiste un enfoque eurocentrista aun cuando sus análisis trasciendan el contenedor clásico del espacio histórico como lo ha sido el Estado-nación (Hausberger, 2013, p. 85; Sachsenmaier, 2007, pp. 466, 469; Sachsenmaier, 2013, p. 4). Pese a ello, parecería que esta hipotética marginación relativa disminuiría para el periodo que comprende el último cuarto de la centuria pasada. Lo anterior encuentra una posible explicación si ponderamos los hechos históricos que caracterizaron a este fin de siècle, donde destaca la cantidad de problemas socioeconómicos que sorteó Latinoamérica. En principio estas dificultades deberían recibir una mayor cobertura, especialmente a partir de la crisis global de la deuda externa en 1982, mediante, por ejemplo, trabajos de análisis contemporáneos, la prensa internacional del momento y los estudios con una perspectiva histórica. Sin embargo, dichas vicisitudes se conciben como fenómenos inherentes a una periferia que acumuló a través del tiempo una serie de desequilibrios socioeconómicos y no necesariamente como manifestaciones de un centro gravitacional importante. A pesar de ello, es factible subrayar el papel clave que desempeñó América Latina en el marco de una estrategia de cambio institucional mundial, cuyo instrumento emblemático fueron los programas de ajuste estructural o programas universales (Riojas, 2000) que se orquestaron desde las principales agencias financieras internacionales en coordinación con los intereses político-estratégicos de Estados Unidos y otros países occidentales (Gruzinski, 2004, p. 417). Estos últimos actores, tomados como un conjunto, mantuvieron una notable influencia en la trayectoria histórica latinoamericana de finales del siglo $\mathrm{XX}$, en complicidad con gobiernos abiertamente autoritarios como fue el caso de Augusto Pinochet en Chile. Los procesos de cambio institucional se intensificaron y se ampliaron hasta alcanzar dimensiones planetarias, donde los países exsocialistas de tipo soviético en Europa central fueron otras destacadas experiencias en este contexto de transformación. Los actores internacionales mencionados fungieron como una especie de comités disciplinarios en el ámbito financiero de la globalización (Harvey, 2012, p. 23), lo que catapultó aún más su poder de decisión y de acción. 
América Latina fue una pieza esencial en este escenario, así como lo fue también en otros contextos históricos, como las fases tempranas de la globalización (Hausberger, 2013, p. 95).

No obstante la serie de eventos que nos da cuenta del protagonismo de América Latina a lo largo del siglo XX, pero especialmente en su última recta, creemos que para este, y todos los periodos hasta ahora mencionados, existe un déficit explicativo en cuanto al ofrecimiento de interpretaciones históricas interconectadas, cruzadas o imbricadas con diversos fenómenos a escala global. Es decir, persiste una configuración geopolítica e institucional de los principales centros de conocimiento internacional, que se hizo más evidente con el colapso de los sistemas socialistas de tipo soviético, además, se manifiestan fenómenos tales como un mayor interés político-económico (Pérez, 2014, p. 344) en ciertos espacios de estudio, la prevalencia de arraigadas jerarquías que no reciben con facilidad otras aproximaciones metodológicas del exterior (como el de la teoría de la dependencia o los estudios subalternos, por ejemplo), se tiende a ignorar la literatura académica de otras partes del mundo, se impulsa una visión hegemónica de un pasado global (Sachsenmaier, 2007, pp. 469, 473, 475; Sachsenmaier, 2013, p. 4), entre otros factores que se han reconocido con cierto criticismo en diversas partes del mundo. Creemos que dicha situación, en el límite, ha generado lo que pudiéramos llamar una periferización inducida de América Latina en las historias mundiales o globales. Con la finalidad de comprobar qué tanto América Latina ha quedado relativamente marginada de las narrativas más influyentes con una perspectiva histórico-global, según hemos expuesto basados en las observaciones de los autores citados, haremos un balance del número de artículos dedicados a este continente en dos publicaciones que se especializan en la materia. La primera de ellas es la revista científica denominada Journal of World History, mientras que la segunda, en una línea similar, es la Journal of Global History. A continuación, proponemos dar un breve recorrido por cada una de las revistas mencionadas no sin antes presentar de manera sucinta la principal línea editorial que las inspiró desde sus inicios.

\section{JOURNAL OF WORLD HISTORY}

Journal of World History apareció por primera vez en la primavera de 1990. Se vivía un momento histórico clave en el contexto del siglo XX, marcado por profundos cambios institucionales, habían pasado escasos meses de la caída del muro de Berlín y se experimentaba una debacle generalizada de los sistemas socialistas de tipo soviético de Europa central y oriental, es decir, la guerra fría $(1947-1989,1991)$ había terminado oficialmente, 
según la visión de las grandes potencias mundiales. En el texto de presentación de la revista, su editor en jefe de aquel entonces, Jerry H. Bentley (1990) ofrecía un nuevo foro para la historia global. Además, creía que era esencial superar un tipo de historia basada en las apologías de posturas políticas e ideológicas típicas del periodo conocido como guerra fría. Esta forma tradicional de estudiar el pasado, según Bentley, era susceptible de encapsular a los historiadores profesionales en la poderosa atracción que ejercía la centralización derivada del Estado-nación, lo que a su vez limitaba la narración porque se enfocaba de manera casi inherente a ciertas comunidades enmarcadas en un contexto nacional específico (Bentley, 1990, p. III). El reconocimiento explícito de esta situación derivó en uno de los elementos esenciales de lo que posteriormente se conocería como historia global, a saber: trascender el espacio nacional para interconectarlo con otros espacios de mayor envergadura (Pérez, 2014, p. 339; Sachsenmaier, 2011, p. 21). Esta perspectiva, obviamente, invitaba también a reconocer que en ciertos objetos de estudio histórico el enfoque cultural iría más allá del encapsulamiento nacional, al interconectarse con diferentes escalas espaciales hasta alcanzar una dimensión global. Lo anterior fue constantemente evidenciado en un creciente corpus bibliográfico de corte histórico que comenzó a poner en relieve dicho fenómeno, incluso se propuso utilizar como sinónimos este enfoque de historia mundial con el de historia transcultural (Sachsenmaier, 2007, p. 489). Por lo tanto, una vez reconocidas estas transformaciones sustanciales en los sujetos susceptibles de historiarse, la Journal of World History invitó a los diferentes historiadores a construir una perspectiva global en sus estudios (Bentley, 1990, p. IV), con una cierta dosis de inspiración revisionista, en sintonía con los aires del tiempo en aquellos años.

$\mathrm{Al}$ hojear el primer volumen y número de 1990 de la revista científica en cuestión, tres de los cuatro artículos publicados tienen el aire revisionista señalado (Allardyce, 1990; McNeill, 1990; Neil, 1990), la cuarta contribución se trata de un repaso histórico sobre el papel de las mujeres en el mundo musulmán (Keddie, 1990). Tomaremos como muestra el trabajo de William H. McNeill (1990) con la finalidad de hacer algunas puntualizaciones, que, a nuestro juicio, resultarán emblemáticas y representativas de la línea editorial que pretendía impulsar la Journal of World History desde sus inicios. Además de ello, marcó el sentido y la trayectoria que siguió esta revista al menos hasta 2016. McNeill consideró que su magna obra fue The rise of the West. A history of the human community publicada por primera vez en 1963 (McNeill, 1963); él pensaba que este trabajo fue una expresión típica del sentimiento imperial estadunidense de posguerra (McNeill, 1990, p. 2); es decir, la concibió como un instrumento del imperialismo intelectual, cuya correa de transmisión para aquellos investigadores de- 
dicados a la historia mundial era el estudio de los cambios sociales mediante el contacto entre diversas civilizaciones. De igual forma, este autor reconoció que The rise of the West era el punto de vista de los vencedores, el cual se exacerbó en las primeras décadas de posguerra; como contraparte se generó una victimización de los vencidos, quienes posteriormente reaccionaron mediante movimientos político-sociales concretos a nivel global como fueron los enfoques poscoloniales o la militancia que adquirieron algunos líderes políticos de Asia, África o América Latina bajo la bandera del tercermundismo (Kalter, 2017, pp. 120-121), cuyo antecedente para este último continente se puede rastrear al menos desde las décadas de 1920 y 1930 , mediante algunas expresiones de la internacional socialista en varios países de América Latina (Bendaña, 2016, pp. 54-55).

A partir de las reflexiones que hace McNeill (1990), él mismo señala algunas inconsistencias de su magna obra que era necesario aclarar, y de paso, propone impulsar un renovado debate de la historia mundial con base en otra perspectiva. El primer error al que hizo referencia fue el abandono de una narrativa cronológica por una que hacía alusión a ciertos tópicos de orden material pero ubicados equivocadamente en el espacio. A lo anterior se agrega la notable ausencia de China en su exposición (como país y como civilización), no sólo como un actor clave en el curso de la historia mundial sino también, por el tratamiento relativamente aislado que adquiere en su interpretación. Pero este supuesto y relativo aislamiento de la civilización china se generalizó para otras civilizaciones al concebirlas como entes autónomos sin tomar en cuenta la intrincada historia que se gesta a través del tiempo entre ellas, es decir, dio prioridad al "límite geográfico como un estilo de vida dado" (McNeill, 1990, p. 9). Lo cual desembocó en un mito que en ese momento era necesario abandonar ante la emergencia de diversos sistemas mundiales con una creciente dinámica de conectividad tanto en el número de personas como en la cantidad de intercambios de todo tipo. Un elemento inherente a esta conectividad era precisamente las articulaciones de lo local con lo global, la noción de un mundo monocéntrico, característico del imaginario imperial estadunidense, fue paulatinamente desechada ante la evidencia de un conjunto de centros con dinámicas particulares, una creciente multiplicidad de actores y culturas que paso a paso configuraron un sistema mundial, que de acuerdo con el enfoque revisionista de McNeill, venía conformándose desde hace siglos. Por lo tanto, estas dinámicas de intercambio e interdependencia han sido compatibles con la coexistencia de múltiples culturas, con el pluralismo político y con la rivalidad entre centros, localidades y actores (McNeill, 1990, pp. 19-20). Componentes, que vistos bajo una trayectoria de mediano plazo tomarían un papel central en la construcción de una aproximación metodológica que ahora es reconocible como historia 
global, cuyo desafío fundamental era, y en cierta medida sigue siendo, la abundante información histórica que se ha generado para los diversos periodos de estudio, la cual es necesario sistematizar con la finalidad de construir diversas narrativas con una coherencia aceptable.

Creemos que esta serie de puntualizaciones, sobre dos de los textos que inauguran la trayectoria de la Journal of World History, sirven como un preámbulo adecuado para contextualizar y entender el tipo de artículos que se fueron publicando conforme pasaba el tiempo. Cabe aclarar que en ninguno de los dos textos citados en los párrafos anteriores se hizo mención a América Latina; la discusión giró en torno a contextos históricoinstitucionales de Asia, Europa y Estados Unidos, lo que concuerda con lo señalado en las secciones anteriores de nuestra exposición.

La Journal of World History de 1990 a 2016 publicó 403 artículos. Con el fin de evaluar el peso relativo que adquiere América Latina en estas narrativas elaboramos una contabilidad múltiple, de la cual se obtuvieron 604 observaciones. ${ }^{3}$ Si tomamos como punto de referencia esta última cifra que incluye a África, América Latina, América del Norte, Asia, Europa, Oceanía y los textos que nos remiten a enfoques teórico-conceptuales, tenemos que solamente $4.64 \%$ (28) de los trabajos consultados tuvieron como tema principal a América Latina, sólo por arriba de Oceanía (véase gráfica 1). ${ }^{4}$

$\mathrm{Al}$ descontar los textos con un enfoque teórico-conceptual, la cifra se incrementa de manera ligera hasta llegar a 5.38\%. Independientemente de ello, el continente que acapara la mayoría de los artículos clasificados, tanto de manera general como por área de estudio, es Asia; en lo que corresponde a este último criterio de clasificación llegó a 41.54\% (216), segui-

${ }^{3}$ Es importante subrayar que la cifra total de textos publicados fue de 403 (artículos en general, artículos de discusión, editoriales, introducciones o prólogos, etc., lo único que no contabilizamos fueron las reseñas). Obviamente esta última cifra no corresponde con el total de 604 textos referenciados en nuestro análisis. Lo anterior se explica porque algunos de los materiales se contabilizaron en más de una ocasión cuando el enfoque era expresamente comparado o abarcaba más de un área de estudio mediante elementos geográficos de conexión tales como desiertos, mares u océanos, por ejemplo. Es por ello que hablamos de observaciones múltiples. Aun si consideramos esta aclaración, con el riesgo y la crítica que pudiera conllevar de la cual estamos conscientes, creemos que la visión original de la relativa marginación de América Latina en las metanarrativas de historia global se mantiene si la apreciamos tanto en términos absolutos como relativos. Más adelante abundaremos al respecto.

${ }^{4}$ Como el lector se habrá percatado, la mayoría de las series, salvo la de los enfoques teórico-conceptuales, hacen referencia a continentes. Dentro de esta última clasificación, el único continente que se dividió fue América al tener una división para el norte (Estados Unidos, Canada, Groelandia y Alaska) y otra para los países latinos y el Caribe en general. Aun si sumamos las Américas y lo tomamos como un solo continente, el porcentaje sería ligeramente superior al de África, pero no obstante ello, un tanto alejado de Europa y por ende de Asia. Por lo tanto, consideramos que esta forma de organizar la información no afecta de manera importante nuestro principal argumento, es por ello que decidimos clasificar bajo estos criterios. Más adelante ofreceremos algunas explicaciones sobre el ambiente institucional en el quehacer histórico que se refleja en estos resultados. 

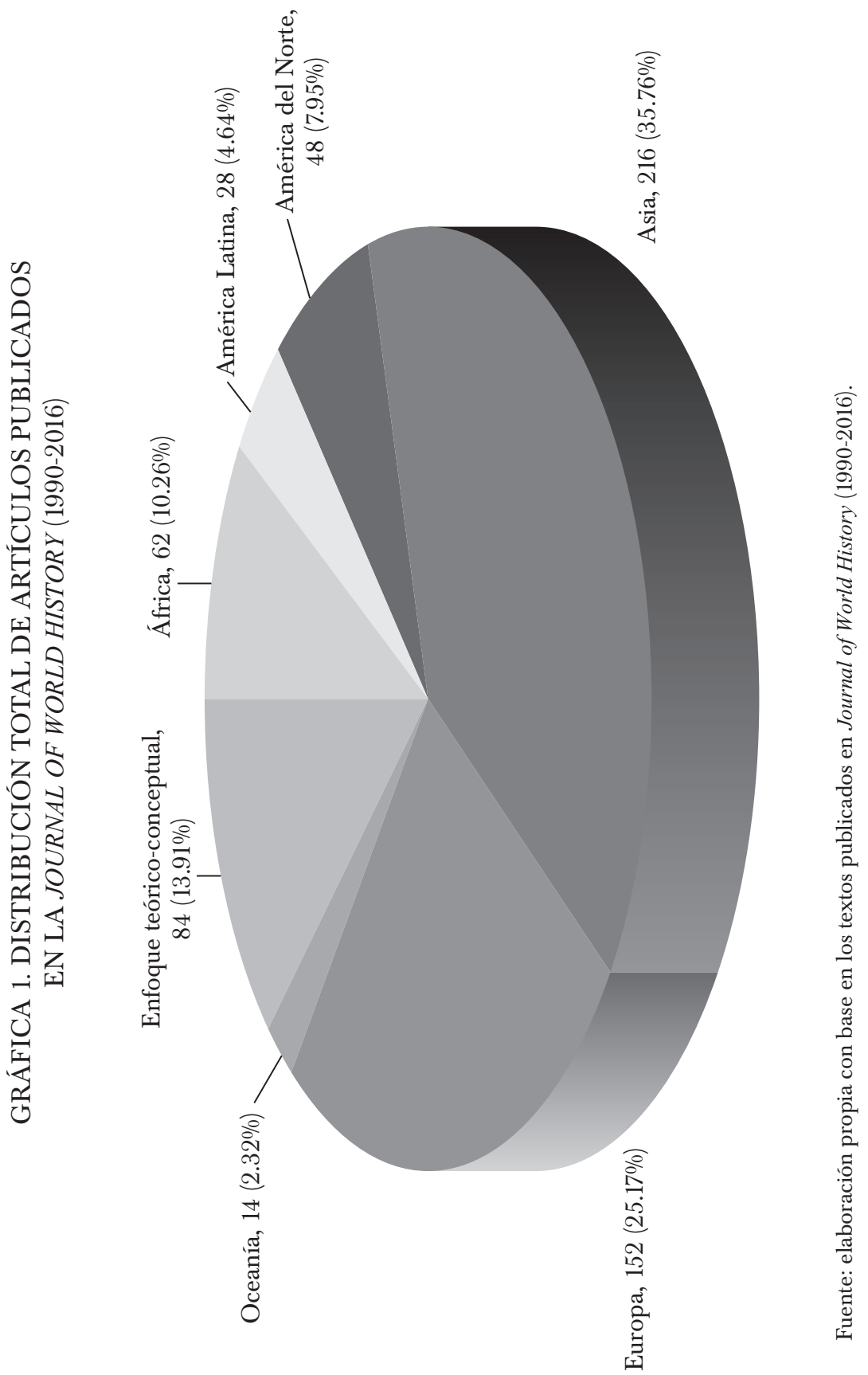
do de Europa con 29.23\% (152) y en tercer lugar África con $11.92 \%$ (62); tan sólo entre Asia y Europa se reparten más de 70\% de las publicaciones agrupadas por área de estudio durante los primeros 26 años de existencia de la Journal of World History (véase gráfica 2).

Incluso, existen varios años donde las publicaciones sobre América Latina fueron inexistentes (1990, 1996-1997, 2001, 2005, 2008, 2011-2012 o 2014-2015, por ejemplo), o es aún más notorio que en los últimos seis años contabilizados (2011-2016) solamente se publicaron dos artículos cuya temática principal hacía alusión a América Latina (véase gráfica 3). Por lo que respecta a esta parte del globo, existe entonces un evidente déficit de representatividad narrativa, lo que implica el no cabal cumplimiento de los objetivos originalmente planteados por la Journal of World History según el editorial de 1990 escrito por uno de sus fundadores como fue Jerry $\mathrm{H}$. Bentley (1990). Estas cifras nos muestran una tendencia que en el mediano plazo parece irreversible.

\section{JOURNAL OF GLOBAL HISTORY}

La segunda publicación que hemos tomado como muestra es la Journal of Global History, cuyo periodo de aparición es menor respecto a la anterior, su primer número se publicó en marzo de 2006. A pesar de ello, a través de sus páginas es notorio cómo según pasaron los años este enfoque de estudio adquirió una mayor complejidad, que es evidente desde sus páginas iniciales. Los desafíos teórico-conceptuales para una aproximación metodológica en construcción se multiplicaron, tal y como lo han subrayado algunos especialistas en la materia (Sachsenmaier, 2007, pp. 470 y 476). En el editorial de presentación firmado por William G. Clarence-Smith, Kenneth Pomeranz y Peer Vries (2006), historiadores destacados, es posible leer entre líneas una doble acepción de lo global. Por una parte, se entiende que lo global no necesariamente atañe a todo el planeta, sino más bien, esta perspectiva aborda las interconexiones que describen y analizan los patrones históricos tanto humanos como no humanos; es una especie de big history que busca la cooperación interdisciplinaria con la finalidad de incrementar nuestro conocimiento. Además, pretende atender la creciente segmentación de las disciplinas, que aún dentro de la historia, se expresa mediante una cantidad infinita de monografías que, vistas desde un enfoque más amplio, son susceptibles de interconectarse y profundizar nuestro entendimiento sobre fenómenos históricos específicos. En breve, uno de los objetivos de la Journal of Global History radicaría, entonces, en superar esta fragmentación historiográfica de dimensiones locales (Sachsenmaier, 2011, p. 232), lo que en el límite marcaría una sutil pero trascendente di- 
옹

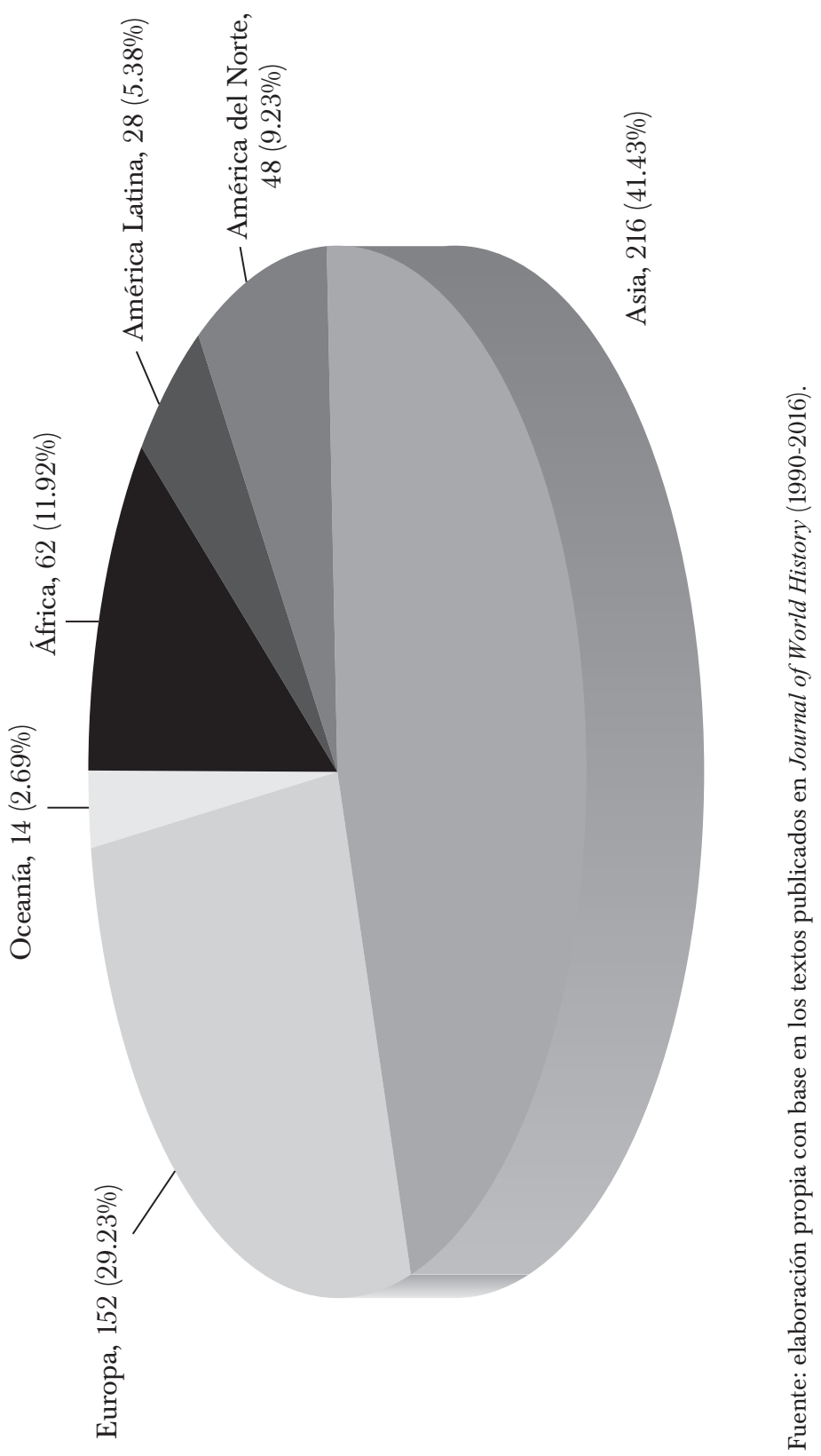



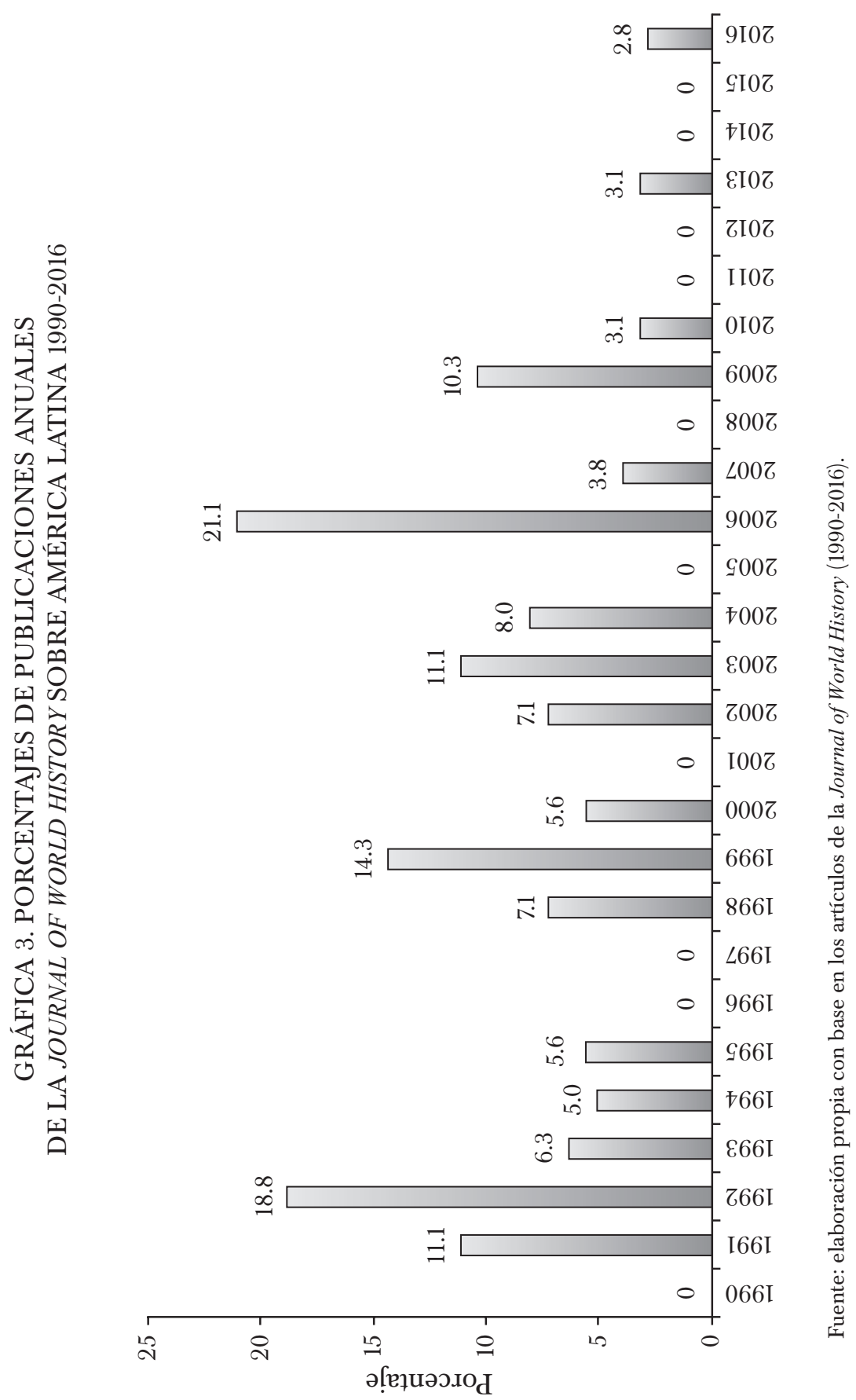
ferenciación con la historia mundial. Esta fragmentación también incluye las áreas disciplinarias como la historia económica que, en el límite, se retroalimentan de otras disciplinas tales como las historias social, política o ambiental, por mencionar algunos ejemplos.

En la segunda acepción destaca que lo global intenta responder a los desafíos lanzados por el proceso de globalización, que se ha vislumbrado un tanto abrumador desde las últimas décadas del siglo Xx. Lo global contiene a la globalización, pero no se limita a esta, porque toma en consideración la multiplicidad de procesos locales que se alimentan, en diversos grados, de eventos de mayor envergadura. Además, se pensaba que estos procesos locales no se han reconocido en sus verdaderas proporciones ante el predominio de las grandes narrativas que le dan un peso casi absoluto al triunfo de Occidente o a la occidentalización del resto, de acuerdo con los argumentos derivados de la ilustración y del eurocentrismo. Lo que en su conjunto ha sido inadecuado o defectuoso según lo concibieron ClarenceSmith, Pomeranz y Vries (2006, pp. 1-2), y ratificado posteriormente por otros estudios del tema (como, por ejemplo, Dominic Sachenmeier [2011, p. 19]). Para estos autores, el Occidente (o mejor dicho el Norte) como el Sur son construcciones históricas que es necesario comenzar a deconstruir de manera crítica, donde se incluyen aquellas metanarrativas deterministas con sustento económico de tipo marxista, o la racionalidad inherente al amorfo individuo, tal como se prescribe en el peculiar imaginario de la economía neoclásica. En resumen, lo global pretende tomar en consideración estas historias locales, diferenciarlas de las narrativas tradicionales a través de un proceso de interconexión y cuestionamiento al pensamiento con sesgo occidentalizante. Connotaciones, ambas, tanto ambiciosas como fascinantes.

Desde su primer número la Journal of Global History pone en la mesa de debate una perspectiva histórica de carácter no tradicional, donde resalta la pretensión de superar el encapsulamiento de lo nacional. Lo anterior se manifiesta en la colección de artículos que componen el mencionado número, donde por ejemplo, se exponen temas como el estudio de las redes de intercambio entre personas y mercancías a través de los océanos, los cuales funcionan como un mecanismo de interconexión entre continentes (Clossey, 2006, pp. 41-58); de igual forma, se aborda el conocimiento en cuanto al manejo de cuencas hidrográficas y su impacto en el ambiente (Davids, 2006, pp. 59-79); a ello se añade la producción algodonera como una especie de commodity cuyo periodo más interesante fue cuando el algodón egipcio ayudó a subsanar el déficit de la oferta mundial derivado de la guerra de secesión en Estados Unidos en la década de 1860 (Owen, 2006), así como el papel de la energía y sus impactos en la vida cotidiana como un agente de transformación tanto social como económica (Malanima, 
2006); o las repercusiones de ideas a nivel global, tal como fue la creación de un nuevo imaginario desde 1789 derivado de la revolución francesa y, posteriormente, los efectos de las guerras napoleónicas a principios del siglo XIX (O'Rourke, 2006). Pese a este grupo de artículos, el texto que pretende marcar la ruta de la revista desde su inicio fue el encomendado a Patrick O'Brien (2006), quien a su vez aborda las diferentes tradiciones historiográficas, pero al mismo tiempo, de manera un tanto paradójica, muestra las insuficiencias en cuanto a la cobertura por áreas geográficas que ha caracterizado a la Journal of Global History al menos durante su primera década de existencia. En concreto nos referimos a la relativa marginación de América Latina, o si se prefiere la periferización inducida, en estas influyentes narrativas que ahí se presentan como historia global. Ahora comentaremos de manera breve este artículo de O'Brien (2006), para después iniciar con nuestro análisis cuantitativo de la representatividad de América Latina en esta revista científica.

A partir de la perspectiva que Patrick O'Brien (2006) nos ofrece, como parte de la colección de artículos inaugurales de la Journal of Global History, es posible subrayar algunos elementos que mantendrán cierta coherencia con la línea editorial que ha caracterizado a esta publicación durante los dos primeros lustros de existencia. De lo anterior se desprenden al menos cinco elementos que serán recurrentes a través del tiempo, a saber: la permanente construcción y refinamiento del enfoque de historia global; un criticismo a ciertas visiones que denominaremos céntricas o centrales en contraparte a las nociones periféricas; atender los desafíos que nos presenta un mundo crecientemente globalizado; un repaso por algunas tradiciones historiográficas más allá de aquellas europeas u occidentales; finalmente, una temeraria negligencia por América Latina que sólo es mencionada dos veces en su artículo (O’Brien, 2006, pp. 14 y 34) cuando trata de aglutinar áreas geográficas en su exposición a fin de darle mayor peso a sus argumentaciones. En seguida daremos más detalles sobre los primeros cuatro elementos, mientras que para el quinto, una vez analizada la representación estadística de América Latina en la Journal of Global History, le dedicaremos el resto de este artículo para tratar de entender por qué este fenómeno se repite también en esta publicación, tal y como sucedió en la Journal of World History.

La permanente construcción y refinamiento del enfoque de historia global se manifiesta en el trabajo de O'Brien (2006) cuando le otorga un peso fundamental a la tarea de reconstrucción de hechos interconectados, los cuales abonarían a ampliar y profundizar el espectro de análisis. A lo anterior, también se agregan las comparaciones que emanan del estudio de múltiples espacios geográficos que fungen como una especie de contenedores; entre ellos despuntan las cuencas, los mares, los océanos, las 
cordilleras, etc. La finalidad de esta aproximación consiste en trascender las tiranías locales o nacionales que quedan limitadas en cuanto a su potencial explicativo ante fenómenos de mayor envergadura manifestados a través del tiempo y del espacio. Son precisamente, según O'Brien (2006, p. 6), los estudios ambientales los pioneros de la perspectiva global al encontrar una estrecha relación entre geografía humana, historia y ciencias naturales en general; asimismo, algunos estudios se sustentan en visiones alternativas del pasado que nos previenen del riesgo que corremos como humanidad ante la imposición de metanarrativas con un enfoque estrecho en cuanto al entendimiento de panoramas donde subyacen eventos históricos con un notable grado de complejidad, dos ejemplos destacados, según nuestra propia perspectiva, de este tipo de análisis es el informe de Roma (Meadows, Meadows, Randers, Behrens III, 1972) y el trabajo de Nicholas Georgescu-Roegen (1971).

El criticismo del autor en cuestión se comprende mejor cuando señala el predominio de aproximaciones eurocéntricas, las cuales se hacen patentes mediante posturas concretas derivadas de los triunfalismos europeo y occidental, cuyos fundamentos encuentran sus orígenes en la ilustración (O'Brien, 2006, p. 11). Por lo tanto, estos enfoques intentan imponerse, tal como lo reconoció también McNeill (1990), al resto del mundo, donde por ejemplo el concepto de civilización es un sinónimo de occidentalización según los esquemas concebidos en los países blancos. La estrecha relación entre la evolución de la modernidad y del Occidente se ha mantenido a través del tiempo, incluso hasta alcanzar la caída del muro de Berlín y el subsecuente fin de los sistemas socialistas de tipo soviético como uno de los momentos cumbre de la modernidad capitalista. Mientras que en países como China se registró de igual forma la influencia de la historiografía de tipo marxista pero más asociada con la rígida sovietización que atendía un devenir histórico en concreto. A las críticas anteriores, O'Brien (2006, p. 24) añade que el cristianismo es concebido como una religión superior respecto al islam, hinduismo, confucianismo o budismo, cuya connotación va más allá del aspecto meramente religioso, e indaga en el dilatado campo que incluye la cultura en general. Recientemente se han publicado algunas obras que ponen en duda esta falacia histórica respecto al islam (Ruthven, 2017).

Esta postura crítica ha encontrado un sustento creciente en algo que podemos denominar el cosmopolitismo académico. No obstante, aún persisten los trazos de los límites y las fronteras nacionales como elementos inherentes en los cursos de historia universal en algunas universidades occidentales. Lo que conlleva, según O’Brien (2006, pp. 32-34), a exclusiones e incluso aislamientos eurocéntricos cuyos resultados se reflejan en el 
progresivo cuestionamiento que se hace a estas propuestas de lo universal. Entonces, una tarea indispensable para nuestro autor es la reconciliación entre diferentes tradiciones historiográficas (negotiable metanarrative) donde cohabitan múltiples modernidades, así como una serie de conexiones entre lo local, lo nacional y lo internacional. Por lo tanto, la inexorable interrelación entre los seres humanos demandaría la construcción de nuevos enfoques conceptuales y educativos, donde la perspectiva de la historia global surgía como un prometedor enfoque analítico, componente clave de una generación de estudios globales.

En este mismo orden de ideas, O’Brien nos describe la trayectoria de algunas tradiciones historiográficas y cómo estas contribuirían, o en su defecto han contribuido, a alimentar la historia global como una metodología de trabajo. La experiencia de África resulta valiosa en este sentido por el proceso de descolonización o por el papel que desempeñó en la construcción forzada de sociedades esclavistas. Para Asia del sur se destacó, entre otras cosas, la estrecha relación que ha mantenido con los británicos, donde también la descolonización ha contribuido de forma esencial en la construcción del enfoque de historia global a través de conceptos como deconstrucción, provincialización, fragmentación, etc., (O’Brien, 2006, p. 32). Mientras que para China y Japón se subraya la persistencia de sólidas y ricas tradiciones historiográficas. No obstante que O'Brien reconoce que los intelectuales musulmanes durante varios siglos mostraron mayor interés, respecto a sus similares europeos, por el conocimiento y estudio de otras culturas (china, india o bizantina), señala que en el mundo islámico el control político-religioso ejerció una fuerte influencia en sus tradiciones historiográficas. Quizá lo más notable en el recorrido hecho por las tradiciones historiográficas por parte de O'Brien es que ignora ampliamente aquellas vinculadas con América Latina, lo que nos motiva a preguntarnos lo siguiente: ¿`será que estas últimas las concibe como parte esencial de las tradiciones historiográficas europeas u occidentales? ¿En qué radica esta visible pero injustificable negligencia sobre América Latina? ¿Acaso esta manifestación fue posteriormente solventada con el devenir del tiempo en la Journal of Global History o se mantuvo como una incómoda característica de la publicación? A continuación, presentaremos un análisis cuantitativo de las publicaciones de dicha revista científica, después trataremos de responder a los cuestionamientos planteados.

Para el análisis cuantitativo utilizamos la misma metodología que en el caso anterior, es decir, dividimos las contribuciones de 2006 a 2016 por áreas de estudio más una sección temática, a saber: África, América del Norte, América Latina, Asia, Europa, Oceanía y el enfoque teórico-con- 
ceptual. Derivado de esta clasificación se computaron 365 artículos dada la contabilidad múltiple explicada anteriormente. ${ }^{5}$

Por lo tanto, el resultado muestra que durante una década se publicaron solamente 27 artículos (7\% del total de contribuciones) cuya temática principal abordaba a América Latina, mientras que en este caso el primer lugar fue ocupado por Europa con 99 contribuciones (27\%), seguida de Asia con $93(26 \%)$ y en tercer plano las discusiones desde una perspectiva teórico-conceptuales con $62(17 \%)$. Cabe mencionar que América del Norte ([38], 10\%) y África ([33], 9\%) mantienen una distribución relativamente similar en esta publicación (véase gráfica 4).

De igual forma, nos gustaría destacar el peso que ha adquirido la discusión teórico conceptual, lo cual es una manifestación del permanente refinamiento de la historia global como enfoque metodológico. Si nos concentramos solamente en los artículos publicados por área de estudio, el argumento principal se sostiene, es decir, el porcentaje de América Latina se incrementa a 9\%, se mantienen aún en los primeros planos Europa (33\%) y Asia (31\%) en ese orden, seguidos por América del Norte (12\%) y África (11\%) (véase gráfica 5).

Cabe destacar que existe una mayor distribución en la Journal of Global History respecto a la Journal of World History, dado que en la primera Europa y Asia concentran 64\% de las publicaciones por área de estudio y el resto se divide entre los otros continentes mencionados en la gráfica 5.

De igual forma, el porcentaje de artículos totales sobre América Latina muestra una mejor distribución durante la década analizada, con una tendencia al alza en los últimos volúmenes, salvo para 2016, donde resalta que en casi todos los años hasta ahora publicados de la Journal of Global History (excepto para 2010) al menos apareció un artículo sobre América Latina (véase gráfica 6).

\section{¿QUÉ FACTORES EXPLICARÍAN LA MARGINACIÓN RELATIVA DE AMÉRICA LATINA?}

Una vez presentados los resultados cuantitativos que nos dan cuenta de la marginación relativa de América Latina en las narrativas más influyentes, como son aquellas publicadas en la Journal of World History y la Journal of

${ }^{5}$ En este caso, el total absoluto de artículos publicados fue de 242, mientras que nosotros referenciamos 365 en el análisis; al igual que en la metodología anterior, algunos materiales se contabilizaron en más de una ocasión cuando el enfoque era expresamente comparado o abarcaba más de una área de estudio. Aunque con una atenuación notable respecto al otro caso analizado, la visión original de la relativa marginación de América Latina se mantiene en términos absolutos y relativos. 


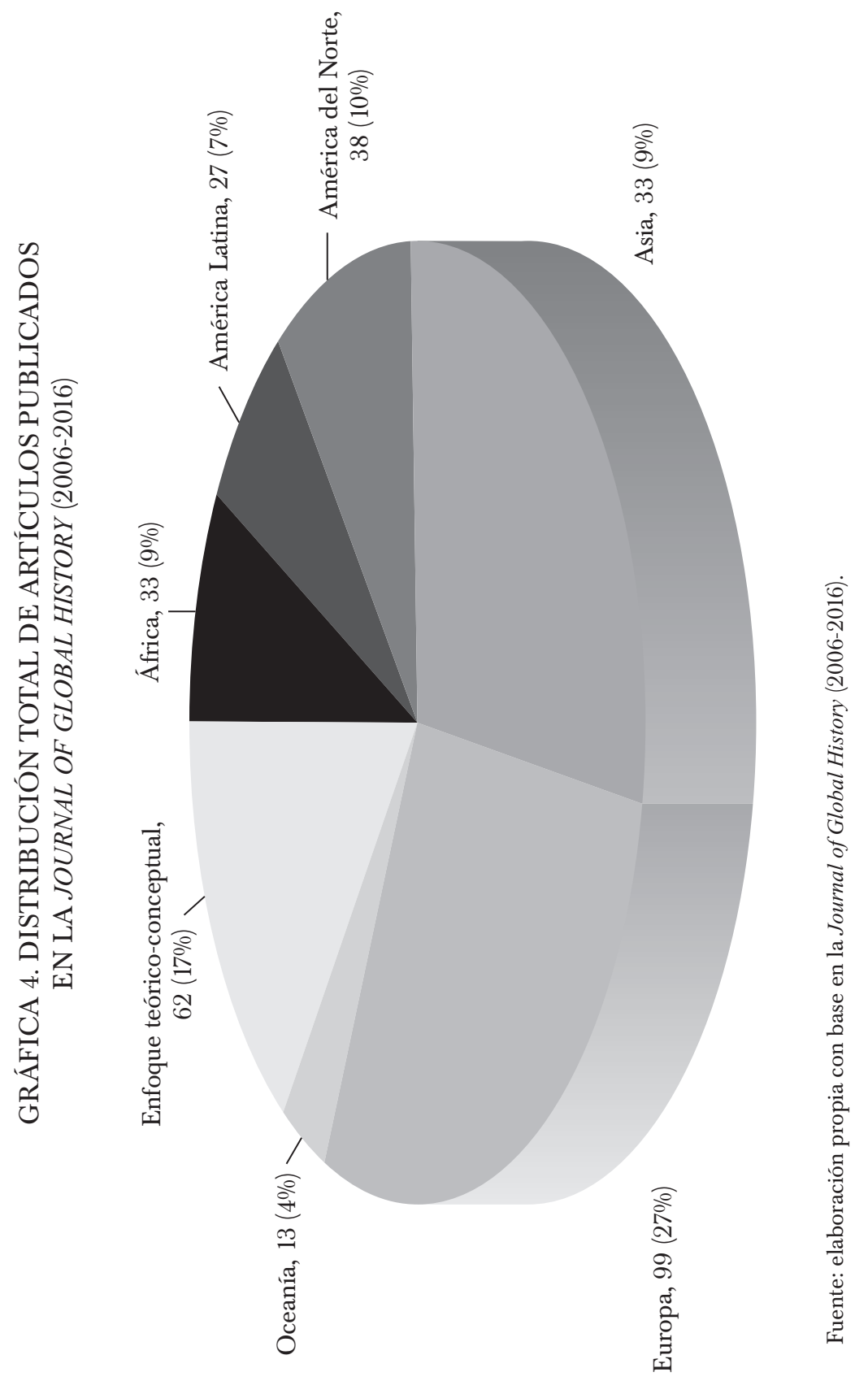




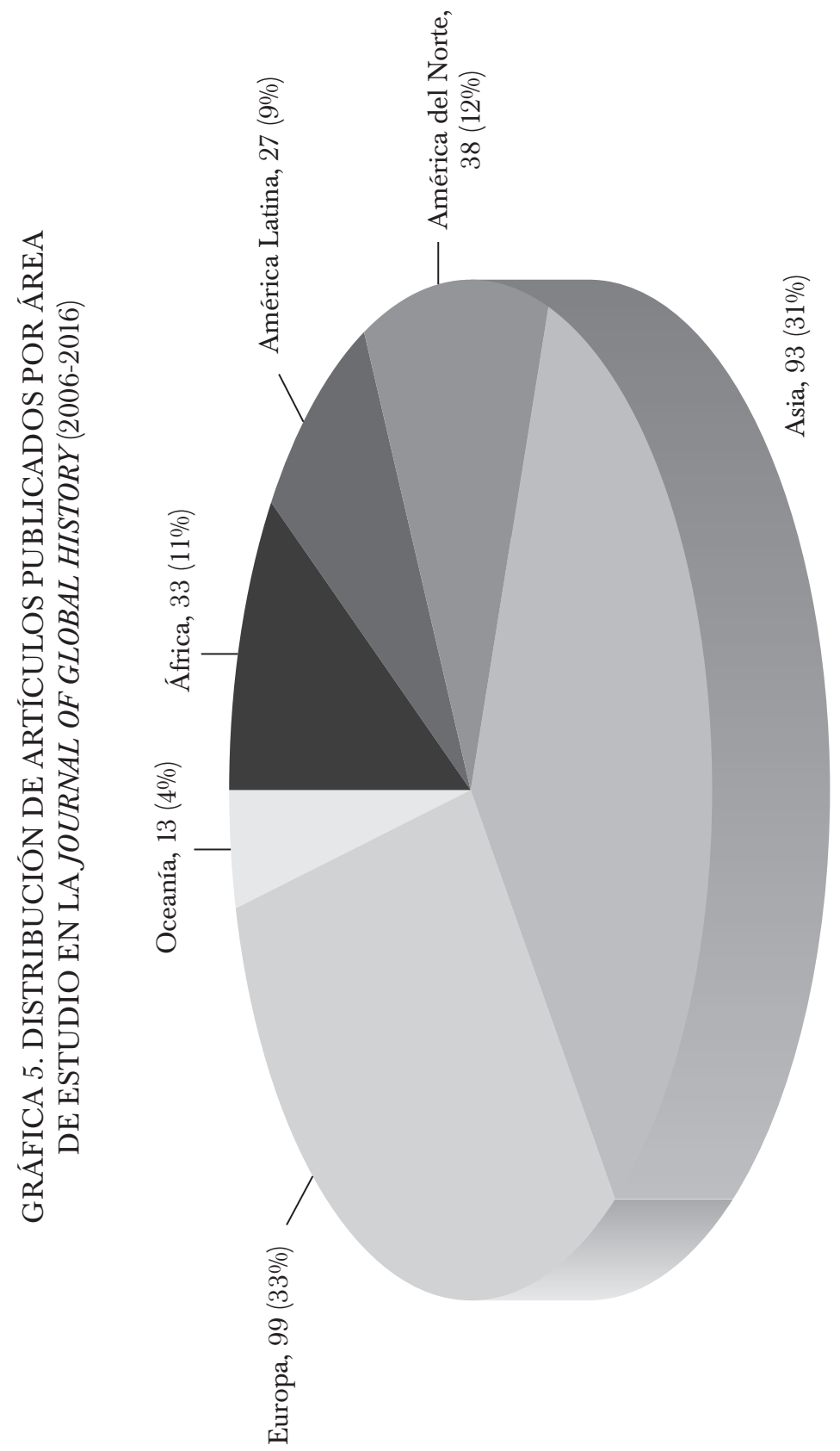

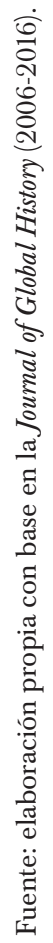



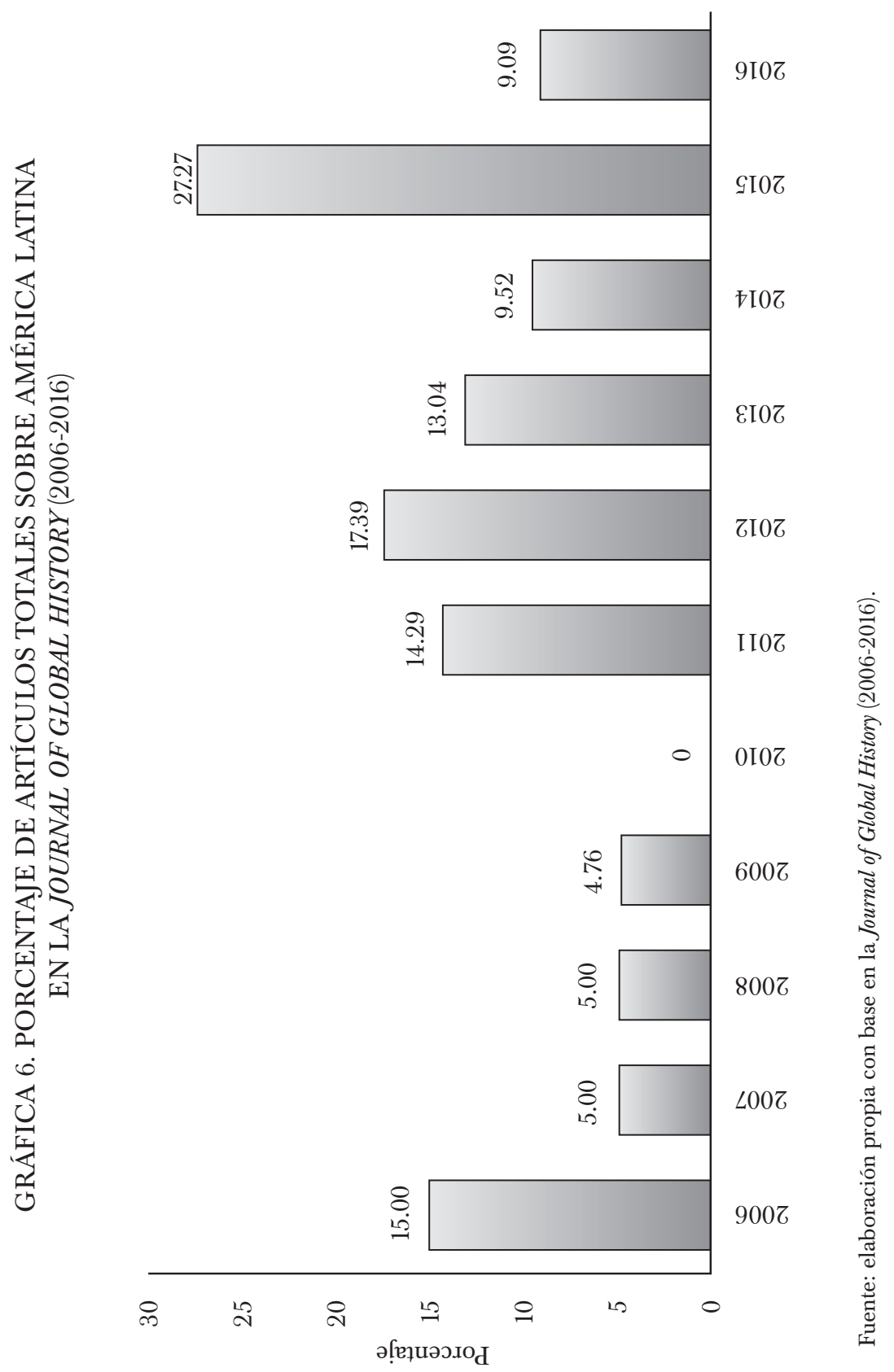
Global History, nos preguntamos lo siguiente: cंcuáles son algunos de los factores que contribuirían a este fenómeno desde un enfoque de historia global? Creemos que un punto de partida adecuado para intentar responder este cuestionamiento lo encontramos en el trabajo de Matthew Brown (2015), quien ha abordado algunos de los elementos que contribuyen a aclararnos el déficit de estudios y conectividad entre la historia de América Latina y la historia global. Dada la trayectoria histórica del continente debería existir, en principio, una estrecha vinculación entre ambas, lo que eventualmente se reflejaría en el número de contribuciones en las principales revistas científicas internacionales especializadas en la materia, pero al menos para las dos evidencias empíricas expuestas aquí no es el caso; así como tampoco lo ha sido en los ejemplos que hemos abordado a lo largo de este ensayo.

No obstante las valiosas y útiles consideraciones de Brown (2015, pp. $365,367,369,370,371$ ), creemos que es factible profundizar en algunos de estos factores explicativos. Para tal efecto, los hemos clasificado en tres rubros, a saber: las configuraciones locales del quehacer histórico, el predominio de una visión anglocéntrica y la institucionalización de la práctica histórica, en este caso desde una perspectiva global donde despunta una visión eurocentrista. Como el lector lo habrá notado, existen estrechas interconexiones entre cada uno de estos rubros, sin embargo, trataremos de presentarlos por separado.

Por lo que respecta a las configuraciones institucionales locales, que dan nacimiento al quehacer histórico, la historia nacional o por área de estudio tienen un peso considerable. Las áreas de estudio se dividen cuando mucho desde una perspectiva geográfico-cultural (historia europea, por ejemplo) en su caso disciplinar (historia económica, sería una de ellas). Sin embargo, también es importante reconocer que existe un conjunto de ideas que han permeado el quehacer de la historia global en América Latina, cuyo carácter híbrido y por supuesto diverso, tiene el potencial de influir en la reconstrucción de narrativas de índole global como una alternativa a estas metanarrativas dominantes. En este caso la posición (la positionality de Conrad [2016, p. 171]) y la situación concreta de los variados historiadores serían parteaguas determinantes en el quehacer histórico de este resto del mundo, que está lejos de presentarse como un espacio pasivo ante las múltiples interpretaciones del devenir histórico que se pretende como global. El punto de vista generado desde lo local ha sido subrayado por otros estudiosos del tema (Sachsenmaier, 2011, pp. 2, 10), cuyo potencial conectivo es variado, aun cuando existan límites institucionales en las fronteras propias del conocimiento histórico dividido por áreas de estudio (Riojas, 2017, p. 395). Dentro de estas mismas configuraciones institucionales, no obstante las destacadas tradiciones historiográficas en el ámbito 
local (que para el caso de la historia económica en América Latina tendríamos la teoría de la dependencia o las interpretaciones de inspiración cepalina), muchos de los investigadores nos asumimos como importadores de construcciones teóricas originadas fundamentalmente en las principales potencias occidentales (los exportadores), que según sea el caso se encuentran impregnadas de lo que Dominic Sachenmaeir (2007, pp. 465, 472) denomina un pasado global eurocentrista, situación que algunos historiadores chinos conciben como una estrategia neocolonial con una cierta dosis de agresión por parte de Occidente (Pérez, 2014, pp. 345, 346), o una versión matizada de este fenómeno sería la imposición de las jerarquías internacionales en la construcción y difusión del conocimiento que, en el caso de la historia, el desenvolvimiento de los Estados-nacionales ha influido de manera determinante en las tradiciones transculturales (Sachsenmaier, 2011, p. 5). Asimismo, desarrollar las habilidades propias de la historia global implica una inversión importante de largo plazo en recursos humanos y materiales para el estudio o la exploración de otros espacios fuera del ámbito local (nacional), donde interviene la internacionalización de las universidades, sus departamentos o facultades respectivas, entrenamiento en diversos idiomas, así como acceso tangible e intangible a diferentes archivos con la finalidad de salir de las comunes órbitas impuestas por los imperios globales (Pérez, 2014, p. 340), o según sea el caso, coloniales; pero es importante también evitar otros tipos de centrismos como el que se ha gestado recientemente en torno a China o Asia en general.

A ello se agregan los idiomas en los cuales se lee y se escribe la historia global o mundial, destaca el predominio de una visión anglocéntrica de la historiografía en cuestión, situación que también es corroborada por otros autores quienes señalan el notable sesgo de un imaginario limitado a la literatura en inglés capaz de delimitar las redes académicas de los historiadores especializados en un pasado global (Potter y Saha, 2015, p. 2; Sachsenmaier, 2007, p. 482), como parte de ciertos códigos de comunicación y medios de expresión que en su extremo reflejan iniciativas de aculturación de tipo occidental (Gruzinski, 2004, p. 414) ante una serie de voces no hegemónicas (Scott, 1990, p. 19) que intervienen de manera marginal en la construcción de dichas narrativas. ${ }^{6}$ Sin embargo, es importante

\footnotetext{
${ }^{6}$ Resulta pertinente aclarar que en nuestra clasificación el caso norteamericano, específicamente estadunidense, se presenta hasta cierto punto paradójico. Por un lado, muestra porcentajes de publicaciones relativamente bajos respecto a Asia y Europa en las dos evidencias empíricas presentadas, los cuales son más cercanos a África y a América Latina, lo que en principio sería una contradicción ante el predominio de la visión anglocéntrica de la historia global. Pero el arraigado encapsulamiento o aislamiento de lo nacional en Estados Unidos también desempeña un papel importante en esta problemática, sobre todo, cuando lo global se explica desde un centro hegemónico reciente y no necesariamente como un proceso de interconexión de historias varias o al menos en dirección contraria. Conforme el análisis histórico se aproxima al presente las evi-
} 
aclarar que las tendencias señaladas no son exclusivas de los historiadores latinoamericanos, sino también son palpables en sus colegas ubicados fuera del continente que estudian América Latina, quienes por lo regular, se encuentran concentrados en centros de investigación adscritos a las áreas de estudio correspondientes. Además, es común que practiquen algunas especializaciones de índole nacional. Esta franca visión anglocéntrica no necesariamente coincide con otras interpretaciones históricas de dimensiones nacionales o continentales, por lo regular, como lo hemos mencionado, estas últimas se adscriben a las áreas de estudio geográfico-culturales. Pero no se trata sólo de una expresión lingüística, sino más bien, en su esencia subyace la difusión de una forma específica de concebir el mundo, vinculada con un pensamiento civilizatorio como uno de los elementos centrales de la civilización, que a su vez se asocia al fenómeno de la ilustración en el más amplio sentido del término (Conrad, 2016, pp. 32175). Esta sutil imposición de una perspectiva occidentalizante conlleva a su vez una noción eurocentrista, que para algunos autores es más adecuado reconocerla como anglocentrista por el papel que desempeña el inglés como lingua franca en las jerarquías de la sociología del conocimiento (Hausberger, 2013, p. 91; Sachsenmaier, 2011, p. 242). Lo anterior se sustenta en el papel dominante que han desempeñado algunas partes de Europa, situación que pudiera concebirse como un modelo universal de desarrollo. Sin embargo, a veces olvidamos que la historia de Europa se caracteriza por su diversidad, no por el impulso de una reciente y aparente homogeneidad a la sombra de lo que conocemos, o de lo que queda, como Unión Europea.

Por último, pero no por ello menos importante, destaca la forma que adquiere el quehacer histórico en temas de historia mundial o global, donde se pone en relieve un tipo de institucionalización mediante la creación de departamentos o centros de estudio específicos en diversas universidades tanto en Oriente como en Occidente. Se hacen patentes las jerarquías globales en una especie de división del trabajo de las disciplinas académicas, lo que toma un sentido cuasi unidireccional al ser Occidente una referencia obligada ("as teaching civilization" [Sachsenmaier, 2011, p. 19]), lo que se traduce en una de las principales paradojas de esto que llaman historia global al reforzar por un lado la visión eurocentrista (o anglocentrista) en detrimento de la naturaleza misma de este enfoque metodológico. Lo anterior ha despertado cierto criticismo y reacción en la comunidad académica

dencias de interconexión de historias globales con las historias estadunidenses se hacen mucho más nítidas, sobre todo durante el siglo Xx. Muestra de ello es la metáfora que se desprende de la lectura de The Economist, en enero de 1979, durante la visita de Deng Xiaoping a Estados Unidos, que el semanario londinense interpretó como una apertura al mundo. Asimismo, este predominio de la perspectiva anglocéntrica toma mayor peso desde el punto de vista cultural y no necesariamente geográfico, al ser Estados Unidos uno de los epicentros difusores de la historia global. 
que trata de organizar redes de conocimiento y cooperación transculturales más abiertas y plurales a fin de alimentar una perspectiva más diversa que no traicione uno de sus principios básicos, no obstante que en el caso de China se sigue viendo esta práctica con una dosis notable de desconfianza, o en el límite, simplemente no se toma en cuenta (Pérez, 2014, pp. 338, 339, 342; Sachsenmaier, 2013, p. 3). Otro factor que ejerce una notable influencia institucional lo encontramos en las explicaciones que le dan sentido a cierta periodización histórica. Algunos periodos toman mayor importancia en función de los hechos narrados y centrados desde una peculiar visión de lo global que impacta directa o indirectamente al resto del mundo. Un ejemplo de ello es la tradicional construcción histórica de lo que conocemos como la revolución industrial, donde Inglaterra en particular y Europa Occidental en general toman un papel protagónico, a expensas de otros procesos similares que se desenvolvían en otras áreas dentro y fuera de Europa con sus dinámicas y problemas inherentes a sus diversos entornos (Riojas, 2016). Consideramos, entonces, que este último factor institucional mencionado tiene una relevancia particular porque mediante la periodización se complementa ${ }^{7}$ una discreta imposición de un imaginario histórico de dimensiones globales susceptible de permear diversas interpretaciones. Creemos que sería pertinente profundizar más en este factor institucional (construcción de periodos históricos), lo que ampliaría nuestro enfoque y de paso serviría para reposicionar a América Latina como un actor estelar, mas no único, en la trama de una nueva historia global.

\section{CONSIDERACIONES FINALES}

La visita de Deng Xiaoping a Estados Unidos (tomada como un preludio a los tiempos que se vivirían posteriormente tras la caída de los sistemas socialistas de tipo soviético), el papel que tradicionalmente se le había asignado a América Latina durante el periodo histórico conocido oficialmente como guerra fría, y el surgimiento de revistas científicas que nos proponían una visión alternativa de un pasado global, son hechos aparentemente independientes, pero que los podemos interconectar con la finalidad de entender la marginación relativa que ha sufrido América Latina como área de estudio en las narrativas más influyentes de la historia global. Dicha marginación relativa fue constatada al explorar dos revistas científicas

\footnotetext{
${ }^{7}$ Señalamos que se complementa porque el idioma o expresión lingüística, como elemento civilizador, también desempeña un papel destacado más allá de su función básica como herramienta comunicativa.
} 
líderes en la materia como son la Journal of World History y la Journal of Global History.

Junto con esta marginación de América Latina destaca el surgimiento de un Este global (Global East) frente a los tradicionales Sur global (Global South) y Norte global (Global North). El crecimiento de la población en Asia ha sido constante, pero una aceleración especial se registró a partir de la década de 1970, lo que ha modificado de manera visible la distribución demográfica del planeta (véase gráfica 7). No obstante este crecimiento poblacional, la producción por habitante en Asia también ha crecido a un ritmo considerable (véase gráfica 8). Cuando Deng Xiaoping visitó Estados Unidos en enero de 1979 este aumento en la producción por habitante ya era palpable, pero a partir de 1990, cuando oficialmente la guerra fría había terminado para dar paso a las estrategias económicas de inspiración neoliberal, el crecimiento de la producción por habitante en Asia se aceleró de forma llamativa, si bien es cierto que aún se encuentra lejos de América en su conjunto y de Europa, recordemos que en términos agregados las brechas se han cerrado en los últimos años.

Fue precisamente en 1990 cuando la Journal of World History publicó su primer volumen con la finalidad de generar un nuevo espacio de discusión alternativo ante las transformaciones experimentadas a nivel global. Estos factores ayudan a entender los dos centrismos que se manifestaron en las revistas analizadas en torno a Asia y Europa, cuyo instrumento conector se dio mediante la visión anglosajona de un contexto que se pretende global.

En lo que respecta a la Journal of World History, desde un inicio, la línea editorial que se propuso seguir descansó en el reconocimiento de ciertos objetos de estudio histórico (circulación de conocimientos, creación de redes, trayectorias de vida, cuencas, mares, montañas, desiertos selvas, etc.), que si bien es cierto que era factible aproximarse a ellos desde un enfoque de área cultural, no menos cierto era que existía una necesidad académica de ir más allá de los encapsulamientos nacionales para interconectar diversos eventos o manifestaciones a escala mundial, y así, ampliar el espectro analítico. No obstante sus pretensiones editoriales, conforme pasaron los años en el número de artículos publicados predominó un sesgo sobre los estudios centrados en Europa y Asia, pero sin abandonar una retórica que se pretende global, donde América Latina quedó relativamente marginada en su discurso (4.68\% de los artículos publicados). Lo anterior ratifica, pero sobre todo mide, algunas de las observaciones hechas por varios historiadores en este sentido, las cuales fueron mencionadas al inicio de este artículo. Por lo tanto, América Latina, a través de las páginas de esta revista, sufrió una periferización, situación que nos conduce a plantearnos lo siguiente: ¿ es realmente la Journal of World History una publicación digna de ese nombre? 


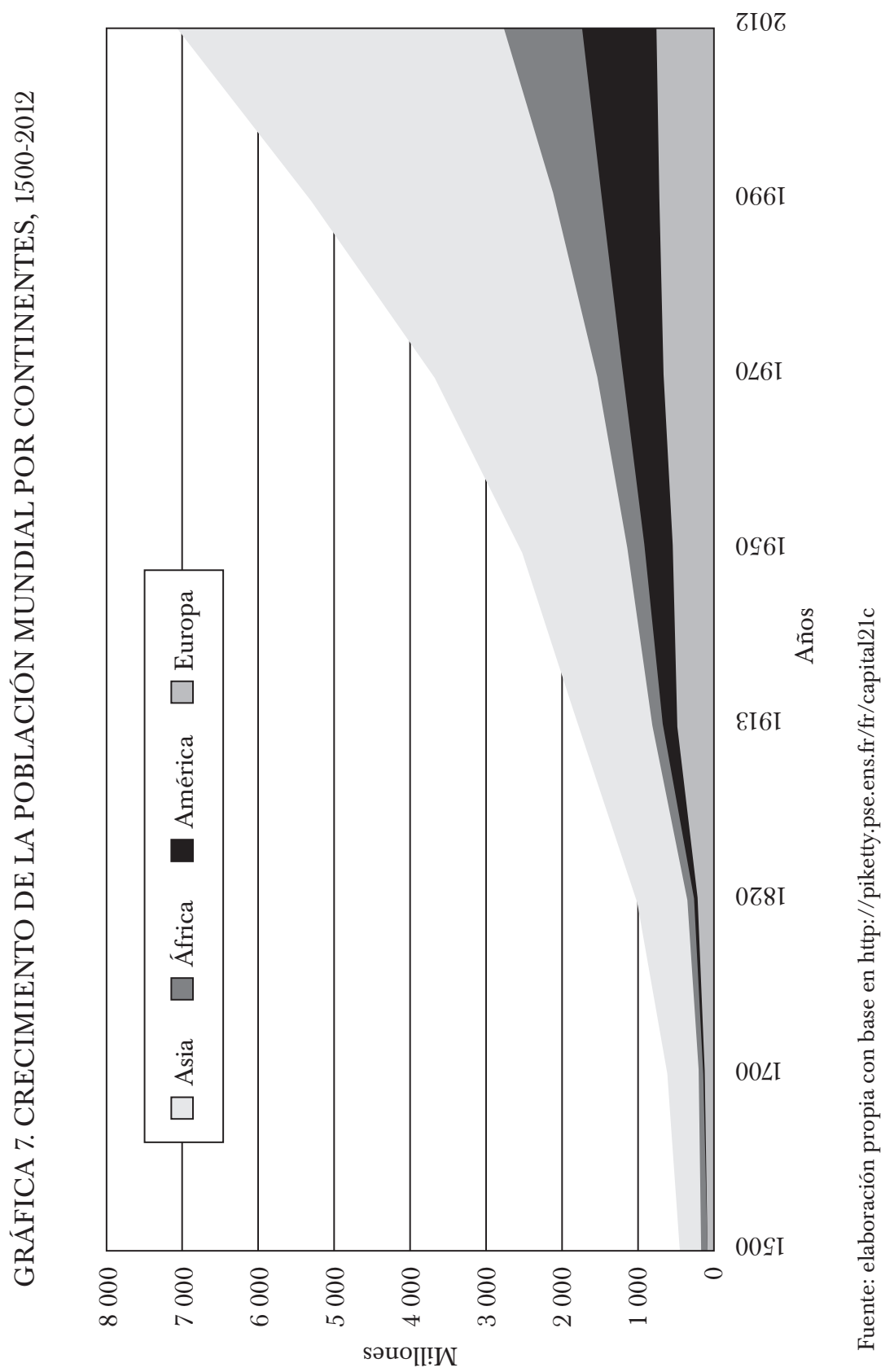




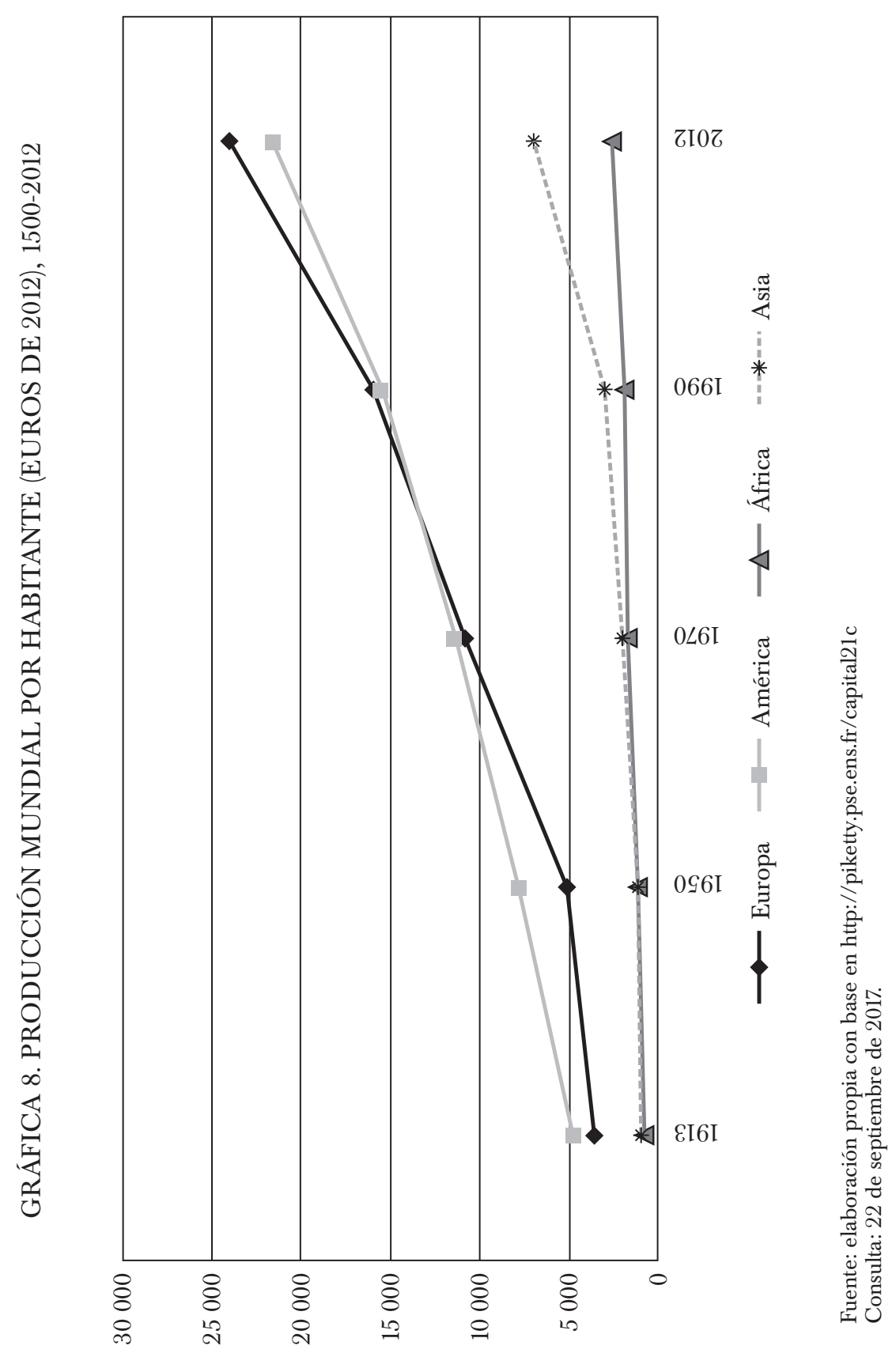


Un resultado similar obtuvimos de la Journal of Global History. Publicación más joven (inició en 2006), pero no por ello menos compleja en su temática y en sus enfoques. Dentro de esta vertiente, resulta pertinente subrayar que una de las acepciones sugeridas por esta revista en lo que concierne a la historia global era trascender la fragmentación temática que impide una comprensión cabal (o menos incompleta) de ciertos fenómenos históricos; otra de sus acepciones radicaba en considerar lo local en el abrumador contexto de la globalización, de esta forma, buscaba reposicionar las manifestaciones locales derivadas de las narrativas tradicionales mediante su interconexión y, a la vez, cuestionar la propagación de un tipo de pensamiento occidentalizante. Desde su inicio se declaró que se abandonarían los tradicionales temas históricos anclados en las historias nacionales, e incluso, por áreas de estudio, a través de propuestas temáticas novedosas. Pero paradójicamente, uno de los textos que pretendió marcar un path dependency en esta revista (O'Brien, 2006) nos ha servido como una clara evidencia para mostrar la marginación de América Latina, lo que posteriormente coincidiría en el número de artículos publicados sobre este continente ( $7 \%$ del total), no obstante su menor sesgo respecto a lo publicado en la Journal of World History. Los temas que O'Brien (2006) trató de poner en relieve en su artículo serían después recurrentes en el devenir de la Journal of Global History: la permanente reconstrucción conceptual de la historia global; la crítica a visiones centristas; la atención prestada a los desafíos que nos ha planteado la globalización; el intento de superar las tradiciones historiográficas; pero, sobre todo, una negligencia en torno a temas que involucren a América Latina como uno de los actores clave de las narrativas más influyentes de historia global, independientemente del periodo de estudio.

Por último, nos gustaría señalar algunos de los factores explicativos que creemos subyacen en esta problemática, los cuales hemos retomado del trabajo de Brown (2015), pero intentamos ampliarlos y profundizarlos. Entre ellos destacaron las configuraciones locales del quehacer histórico; el predominio de las metanarrativas con una visión anglocéntrica, lo que no necesariamente coincide con las interpretaciones de las historias nacionales, por lo regular estas últimas adscritas a las áreas de estudio culturales, y la sutil imposición de una visión occidentalizante donde América Latina, en el mejor de los casos, adquiere un carácter híbrido. A pesar de todo lo mencionado hasta el momento, creemos que aún faltaría investigar más sobre ciertos periodos históricos en concreto, donde América Latina desempeñaría un papel estelar. Dicho de otra forma, nos preguntamos lo siguiente: ¿qué temas se abordan?, y cंcómo se distribuyen estos estudios a 
través de periodos históricos que, eventualmente, nos ayudarían a vislumbrar los potenciales tópicos donde América Latina contribuiría de manera significativa en la reinterpretación o reconstrucción de la historia con un auténtico carácter global? Es decir, una nueva historia global. De hecho el trabajo de Brown (2015) nos sugiere cinco periodos de estudio donde se abre la oportunidad de construir una serie de interconexiones históricas entre América Latina y una perspectiva global, a saber: la conquista que gira en torno a 1500; la influencia del mundo atlántico que abarcaría la segunda mitad del siglo XVI y parte del XVII; el periodo colonial tardío (siglos XVIII y XIX); la revolución industrial, ca. 1830-1870, y el capitalismo liberal a partir de 1870, que trasciende la primera guerra mundial hasta 1920 (Brown, 2015, pp. 377, 378, 379). Pero, concebimos lo anterior como parcial porque también este autor deja de lado otros periodos o eventos clave donde la contribución de América Latina en la historia global es esencial, por ejemplo, la segunda guerra mundial y el impulso a un imaginario tercermundista; la descolonización y el auge de las economías estatales; la guerra fría, y las diversas estrategias de neoliberalización. El análisis de estos periodos es una tarea pendiente que nos gustaría abordar en otra contribución.

\section{LISTA DE REFERENCIAS}

Allardyce, G. (1990). Toward world history: American historians and the coming of the world history course. Journal of World History, 1(1), 23-76. Recuperado de http://www.jstor.org/stable/20078456

Bendaña, A. (2016). Sandino. Patria y libertad. Managua, Nicaragua: Anamá Ediciones. Bentley, J. H. (1990). A new forum for global history. Journal of World History, 1(1), IIIv. Recuperado de http://www.jstor.org/stable/20078454

Berger, D., Easterly, W., Nunn, N. y Satyanath, S. (2013). Commercial imperialism? Political influence and trade during the Cold War. American Economic Review, 103(3), 863-896. DOI: 10.3386/w15981

Bonialian, M. (2017). Historia colonial e historia global. Enfoques desde la historia económica. En C. RiOJAS y S. Rinke (eds.), Historia global: perspectivas y tensiones (pp. 7793). Stuttgart, Alemania: Verlag Hans Dieter Heinz-Akademischer Verlag Stuttgart.

Brown, M. (2015). The global history of Latin America. Journal of Global History, 10(3), 365-386. DOI: 10.1017/S1740022815000182

Clarence-Smith, W. G., Pomeranz, K. y Vries, P. (2006). Editorial. Journal of Global History, 1(1), 1-2. DOI: 10.1017/S1740022806000015 
Am. Lat. Hist. Econ., año 25, núm. 3, septiembre-diciembre, 2018, pp. 7-39

Clossey, L. (2006). Merchants, migrants, missionaries, and globalization in the early-modern Pacific. Journal of Global History, 1(1), 41-58. DOI: 10.1017/ S1740022806000039

Conrad, C. (2016). What is global history? New Jersey: Princeton University Press.

Cox, M. (2011). Fred Halliday, Marxism and the Cold War. International Affairs, 87(5), 1107-1122. DOI: 10.1111/j.1468-2346.2011.01023.x

DAvids, K. (2006). River control and the evolution of knowledge: A comparison between regions in China and Europe, c. 1400-1850. Journal of Global History, 1(1), 59-79. DOI: 10.1017/S1740022806000040

Georgescu-Roegen, N. (1996 [1971]). La ley de la entropía y el proceso económico. Madrid: Fundación Argentaria-Visor.

GruZINSKI, S. (2004). Les quatre parties du monde. Histoire d'une mondialisation. París: La Martinière.

Harvey, D. (2012). El enigma del capital y las crisis del capitalismo. Madrid: Akal.

Hausberger, B. (2013). Acercamiento a la historia global. En C. Alba, M. Braig, S. Rinke y G. ZermeÑo (eds.), Entre espacios. Movimientos, actores y representaciones de la globalización (pp. 83-98). Berlín: Universidad Libre de Berlín/Colegio Internacional de Graduados.

Kalter, CH. (2017). From global to local and back: the "Third World" concept and the new radical left in France. Journal of World History, 12(1), 115-136. DOI: 10.1017/ S174002281600036X

KedDIE, R. (1990). The past and present of women in Muslim world. Journal of World History, 1(1), 77-108. Recuperado de http://www.jstor.org/stable/20078457

Malanima, P. (2006). Energy crisis and growth 1650-1850: The European deviation in a comparative perspective. Journal of Global History, 1(1), 101-121. DOI: 10.1017/ S1740022806000064

MCNeILL, W. (1963). The rise of the West. A history of the human community. Chicago, Estados Unidos: Chicago University Press.

MCNEILL, W. (1990). "The rise of the West" after twenty-five years. Journal of World History, 1(1), 1-21. Recuperado de www.jstor.org/stable/20078455.

Meadows, D. H., Meadows, D. L., Randers, J. y Behrens III, W. W. (1972). The limits to growth. A Report for the club of Rome's project on predicament of mankind. Nueva York: Universe Books.

NeIL, R. VAN (1990). Colonialism revisited: Recent historiography. Journal of World History, 1(1), 109-124. Recuperado de http://www.jstor.org/stable/20078458

O'Brien, P. (2006). Historiographical traditions and modern imperatives for the restoration of global history. Journal of Global History, 1(1), 3-39. DOI: 10.1017/ S1740022806000027

O'Rourke, K. H. (2006). The worldwide economic impact of the French revolutionary and napoleonic wars, 1793-1815. Journal of Global History, 1(1), 123-149. DOI: 10.1017/S1740022806000076 
Owen, R. (2006). The rapid growth of Egypt's agricultural output, 1800-1914, as an early example of the green solutions of modern South Asia: Some implications for writing of global history. Journal of Global History, 1(1), 81-99. DOI: 10.1017/ S1740022806000052

Pérez, M. (2014). From eurocentrism to sinocentrism: The new challenges in global history. European Journal of Scientific Research, 119(3), 337-352. Recuperado de https://www.researchgate.net/publication/264197037

Piette, A. (2011). Writing into the cold war West. Theory, Culture E Society, 28(7-8), 390395. DOI: $10.1177 / 0263276411417464$

PotTer, S. J. y SAHA, J. (2015). Global history, imperial history and connected histories of empire. Journal of Colonialism and Colonial History, 16(1), 1-14. DOI: 10.1353/ cch.2015.0009

Rinke, S. (2017). "Un monstruoso atentado contra la cultura humana”: el comienzo de la guerra mundial en 1914 en Latinoamérica. En C. RIOJAS y S. Rinke (eds.), Historia global: perspectivas y tensiones (pp. 121-135). Stuttgart, Alemania: Verlag Hans Dieter Heinz-Akademischer Verlag Stuttgart.

Riojas, C. (2000). De programas universales a programas locales. En A. Kon, C. BANKO, D. Melcher y M. C. Cacciamali (eds.), Costos sociales de las reformas neoliberales en América Latina (pp. 309-326). São Paulo, Brasil: Pontificia Universidad Católica de São Paulo/Universidad Central de Venezuela.

Riojas, C. (2016). Estudios proto-industriales: origen y legado. Ciudad de México-Madrid: Plaza y Valdés.

Riojas, C., (2017). Desafíos de la historia global: una perspectiva desde América Latina. En Centro de Investigación y Desarrollo de Ecuador, Retos y perspectivas del desarrollo económico en Ecuador y América Latina (pp. 389-400). Ecuador: Autor.

Roberts, J. M. y Westad, O. A. (2013). The Penguin history of the world. Londres, Reino Unido: Penguin.

Rochlin, J. F. (2011). Who said the Cold War is over? The political economy of strategic conflict between Venezuela and Colombia. Third World Quarterly, 32(2), 237260. DOI: 10.1080/01436597.2011.560467

Rogers, P. (2014). A century of the edge: from cold war to hot world, 1945-2045. International Affairs, 90(1), 93-106. DOI: 10.1111/1468-2346.12097

Ruthven, M. (22 de junio de 2017). The Islam road to the modern world. The New Yorker Review of Books. Recuperado de: http://www.nybooks.com/articles/2017/06/22/ islamic-road-to-modern-world

SaChSEnMAier, D. (2007). World history as ecumenical history? Journal of World History, 18(4), 465-489. DOI: 10.1353/jwh.2008.0002

SACHSENMAIER, D. (2011). Global perspectives on global history. Theories and approaches in a connected world. Nueva York: Cambridge University Press.

Sachsenmaier, D. (5 de septiembre de 2013). Some reflections on the nature of global history. The Daily, Toynbee Prize Foundation. Recuperado de http://toynbeeprize. org/blog/some-reflections-on-the-nature-of-global-history/ 
Am. Lat. Hist. Econ., año 25, núm. 3, septiembre-diciembre, 2018, pp. 7-39

ScotT, J. C. (1990). Domination and the art of resistance. Hidden transcripts. Yale: Yale University Press.

Semo, E. (1989). Conquista y colonia. En E. Semo (ed.), México, un pueblo en la historia. De la aparición del hombre al dominio colonial (vol. 1, pp. 148-325). Ciudad de México: Alianza. 